\title{
Tendon Rupture as a Probable Side Effect of Ciprofloxacin: A Review Article
}

\author{
Nazanin Foroutan* \\ Faculty of Pharmacy, Kerman University of Medical Sciences, Kerman, Iran
}

\begin{abstract}
Ciprofloxacin is a broad-spectrum antibiotic from fluoroquinolones which are used to treat gram negative and positive bacterial infections. In last twenty years, tendinopathy is a worrying side effect. The side effects of tendon disorders including pain on tendon, angle tenderness, tendinitis and tendon rupture risk. Based on these symptoms various cases are shown and calculated. After several weeks pause in ciprofloxacin treatment the symptoms of tendon disorders are reduced.
\end{abstract}

Keywords: Ciprofloxacin; Antibiotic; Fluoroquinolones; Tendon rupture; Tendinopathy; Tendinitis; Side effects

\section{INTRODUCTION}

Ciprofloxacin is a broad spectrum antibacterial agent against gram negative bacteria and also gram positive (recently), anaerobic bacteria which belongs from the class of fluoroquinolones which are used for treatment of different bacterial infections ranging from urinary tract infections to respiratory tract infections [1-3]. It functions by inhibiting DNA gyrase and a type II topoisomerase, topoisomerase IV, necessary to separate bacterial DNA, thereby, inhibiting cell divisions [4-6]. Common side effects of fluoroquinolones are gastrointestinal effects (such as vomiting, nausea and diarrhoea), central nervous system reactions (from mild one such as sleeplessness, headache and dizziness to sever). Also Ciprofloxacin can cause skin tumors due to photosensitivity. Unlike other antimicrobial agents, fluoroquinolones have shown CNS effects (dizziness, headache, drowsiness, insomnia, organic psychosis and convulsions) as the second most frequently form of toxicity $[7,8]$. This might be due to the blood-brain barrier penetration or lipophilicity of fluoroquinolones [9-11]. Additionally, according to several case reports and investigations, tendinitis or tendon ruptures might be a probable side effect [12-14]. It is proved by laboratory tests and case reports.

The exact mechanism of ciprofloxacin in causing tendon rupture is not certainly determined. But the possible proposed mechanisms are effects of ciprofloxacin on expression of MMP-2,9, TIMP-1,2 and tissue inhibitor type I collagen in tendon cells and decrease in interleukin $1-\beta[15,16]$.

\section{METHODS}

We searched in different databases like Google Scholar, PubMed,
Science direct and Scopus using 'ciprofloxacin', 'tendon rupture' and 'tendonitis' as key words. All available articles related to these were included. The characteristics of reviewed articles or case studies have mentioned in Table 1.

\section{CASE REPORTS}

There are several case reports as following which are mentioned with the respect of low to high doses of Ciprofloxacin. Damuth, et al. reported a case that a woman suffered from kidney disease and consumes $250 \mathrm{mg}$ ciprofloxacin per day for several days. This elderly person undergoes tendinitis which was improved after two days of ciprofloxacin cessation. He also concluded that fluoroquinolone should be used with caution in UTI especially in patients with advanced age and renal dysfunction [17]. Among all of the most important reports, a case report was about an old man who was administered $250 \mathrm{mg}$ ciprofloxacin twice daily for his lower respiratory tract infection. After six days, he felt pain and snap on his calf which was the symptoms of tendon rupture, known after the examination [18]. Also, Karistinos and Paulos [19] revealed in the case report that a patient had taken a four weeks treatment for prostate infection with oral ciprofloxacin $(800 \mathrm{mg} /$ day). After 30 days completion of the treatment, complain was reported regarding the bilateral proximal anterior thigh deformity and also mild knee extension weakness in the year 2017.

Moreover, administration of ciprofloxacin $500 \mathrm{mg}$, i.e. twice a day, to a middle aged man with diabetes mellitus caused tendinitis with sharp pain sensation is a related case, reported by Mouzopoulos et al. [20]. Another interesting case was 32 years old man who suffered from Achill's tendon rupture in his right and left tendon

Correspondence to: Nazanin Foroutan, Faculty of Pharmacy, Kerman University of Medical Sciences, Kerman, Iran, E-mail-nfrootan.nazanin@gmail.com

Received: January 17, 2019; Accepted: April 10, 2019; Published: April 18, 2019

Citation: Foroutan N (2019) Tendon Rupture as a Probable Side Effect of Ciprofloxacin: A Review Article. Adv Pharmacoepidemiol Drug Saf 8:1.

Copyright: ( 2019 Foroutan N. This is an open-access article distributed under the terms of the Creative Commons Attribution License, which permits unrestricted use, distribution, and reproduction in any medium, provided the original author and source are credited. 
Table 1: The characteristics of reviewed articles or case studies list.

\begin{tabular}{|c|c|c|c|c|c|c|}
\hline Author & $\begin{array}{l}\text { Reason ciprofloxacin } \\
\text { consumption }\end{array}$ & $\begin{array}{l}\text { Duration of } \\
\text { consumption }\end{array}$ & $\begin{array}{l}\text { Amount of } \\
\text { consumption }\end{array}$ & Other risk factors & $\begin{array}{c}\text { Severity of } \\
\text { tendino- } \\
\text { pathy }\end{array}$ & Recovery \\
\hline $\begin{array}{l}\text { Muzi et al. } \\
\text { [23] }\end{array}$ & Urinary tract infection & 7 and 10 days & $500 \mathrm{mg}$ twice a day & $\begin{array}{l}\text { Renal failure, } \\
\text { hyperpara-thyroidism } \\
\text { and corticosteroids }\end{array}$ & $\begin{array}{c}\text { inter } \\
\text { mediate }\end{array}$ & Two months \\
\hline Damuth et al. [17] & Urinary tract infection & 7 days & $250 \mathrm{mg}$ per day & Age & Intermediate & 8 days \\
\hline $\begin{array}{c}\text { Akali and Niranjan } \\
\text { [18] }\end{array}$ & $\begin{array}{l}\text { Lower respiratory } \\
\text { tract infection }\end{array}$ & 7 days & $250 \mathrm{mg}$ twice a day & corticosteroids & sever & - \\
\hline Movin et al. [22] & $\begin{array}{c}\text { Osteomyelitis/after } \\
\text { surgery }\end{array}$ & 12 weeks $/ 7$ days & $500 \mathrm{mg}$ twice a day & - & Intermediate & 2 weeks \\
\hline
\end{tabular}

within one year interval of using $1000 \mathrm{mg}$ ciprofloxacin orally for 10 days to treat typhoid; one month before the first incidence and repeat the same treatment for urinary infection one month before the second incidence [21]. The same problem was appeared in two other patients with consumption of ciprofloxacin with dosage of $1000 \mathrm{mg}$ per day for one week in the first case and $1000 \mathrm{mg}$ daily for 4 weeks which continued with $1500 \mathrm{mg}$ for other 8 weeks in the second one [22].

Beside all these reports, Muzi et al. reported two cases of tendinitis and tendon rupture in kidney transplant recipients. The first one was a woman who received $500 \mathrm{mg}$ twice a day for 10 days; after six months of transplantation for a urinary tract infection which leads to joint pain and edema after five days of treatment. These symptoms reversed one month later due to fluoroquinolonestherapy for recurrent Urinary Tract Infection (UTI). The latter one was a woman who received ciprofloxacin for 7 days. After that she experienced pain in Achilles tendon with edema [23]. Also other same reports strengthen the relative conclusion of tendinopathy with ciprofloxacin $[2,24,25]$.

\section{RESULT AND DISCUSSION}

\section{In-vitro surveys}

To evaluate the aspects of mechanism of quinolone-induced tendotoxicity, a piece of tendon from a Caucasian patient was used. Monocytes were incubated by different concentrations (0, 3, 10,30 and $100 \mathrm{mg} / \mathrm{L}$ ) of ciprofloxacin for up to 4 days. Effects were investigated by electron microscopy and immune-blotting. The results show structural changes (like condensed materials in nucleus, swollen cell organelles and apoptotic bodies at the cell membrane which induced tendinopathy) by the concentration of $3 \mathrm{mg} / \mathrm{L}$ which were intensified by higher concentrations and incubation period [26].

Other cellular experiment was set in Taiwan in which cultured cells of Rat Achill tendon were left treat or untreated with 5, 10, 20 and $50 \mu \mathrm{g} / \mathrm{ml}$ ciprofloxacin. Several tests such as MTT assay, RTPCR analysis, western blot analysis and gelatines zymography are used. The results shows that ciprofloxacin can have negative effects on tendon through the mechanism by up regulating gelatinase expression and it was confirmed by the evidence of increased degradation of type I collagen [15]. The same study was set up by human tendon fibroblast with $50 \mu \mathrm{g} / \mathrm{ml}$ ciprofloxacin which shows the ciprofloxacin can enhance the expression of MMP-1 and MMP3 at not only the m-RNA but also the protein level [27]. Corps et al. used human tendon cell incubating with $50 \mu \mathrm{g} / \mathrm{ml}$ ciprofloxacin. After challenging with interleukin $1-\beta$ for 48 hours, prostaglandin E-2 output was assayed. The way in which fluoroquinolones can causes tendinopathy may be the fact that ciprofloxacin decreases the interleukin-1 $\beta$ induced prostaglandin E-2 output in tendon cells [16]. Riley set an in-vitro study to determine the effect of ciprofloxacin on fibroblast metabolism. He incubated Achilles tendon, Achilles paratenon and shoulder capsule fibroblast in culture with 5,10 and $50 \mu \mathrm{g} / \mathrm{ml}$ ciprofloxacin that resulted in 66 $68 \%$ decrease in cell proliferation compare with control cells after 72 hours [28].

Pouzaud et al. from France set an in-vitro stress oxidative involvement experiment evaluating the toxicity of fluoroquinolones on tendon cells. Immortalized rabbit tendon cell line affected by fluoroquinolones was used to assess cell viability, redox status changes, reduced glutathione changes and reactive oxygen species production (with using Neutral red, Alamar blue, monobromobimane and 2,7-dichlorofluorescindiacetate fluorescent probes, respectively). Cold light cytofluorometer was used to analyze living tenocytes in which the fluoroquinolones showed moderate cytotoxicity after one day and more sever toxicity after another 48 hours. Interestingly, intrinsic toxicity with ciprofloxacin in comparison with other fluoroquinolones was high [29].

\section{Statistical experiments}

A survey during 1998-2000 in France on 525 pediatric patients who were categorize in to groups of control and patients who expose to fluoroquinolones using a pharmacy database revealed the fact that the relative risk of tendon and joint disorder with ciprofloxacin was 1.04 [30]. Similar experience in United Kingdom on 50000 patients shows the odd ratio of quinolones for Achill tendon rupture is 8.1; while, this ratio for current use of ciprofloxacin was 3.6\% that age and consumption of corticosteroids increases the risk [31].

A case-control study in Italy during 2002-2003 investigated the tendon disorders with current use of fluoroquinolones. 22194 cases and 104906 controls had participated in this study. It was demonstrated that odds ratio of Achilles tendon rupture is around 2\% which means it would occur for every 5958 patients treated by fluoroquinolones. The corresponding number in concurrent treatment with corticosteroids is 979 and 1638 for patient with age over 60 [32].

A study has evaluated 42 cases of tendon disorders in Netherlands 
during the period of 1988-1998. It showed that the median period of latency between the use of fluoroquinolones and start of the first symptoms is 6 days and most recoveries had happened on average of 2 months after fluoroquinolones cessation [1].

During 2010 in Australia, Achilles Tendon Disease (ATD) was studied in lung transplant recipients. It shows 53\% of Achilles tendon rupture was associated with the use of ciprofloxacin. But the relation was not dose related and Chhajed -the writer- concluded that the incidence may be idiosyncratic [33].

\section{Risk factors}

Some factors has mentioned which increase the risk of tendon injury in consumption of ciprofloxacin; age (over 60 years), renal failure, diabetes mellitus, organ transplantation, corticosteroids therapy or long history of diuretics treatment, hyperparathyroidism, rheumatic disease, gout, trauma, systemic lupus erythematous, psoriatic arthritis, ankylosing spondylitis, ulcerative colitis, long period of dialysis and Crohn disease [2,19,21, 23,31,34].

\section{Evidence test}

During 2011, Zargar set an experiment to determine whether plateletRich Plasma can protect tenocytes from effects of ciprofloxacin and dexamethasone. Five doses of ciprofloxacin (10, 20, 30 and $40 \mu \mathrm{g} /$ $\mathrm{ml}$ ) and 10-2 $\mathrm{M}$ dexamethasone exposed to cells for 3 days and after that cell viability was assessed by Alamar Blue. She substantiated that high dose of ciprofloxacin decreases tenocytes viability in comparison with controls whereas dexamethasone increases the senescent cells considerably [35].

\section{Electron microscopy study}

Shakibaei et el. have shown that there are various alterations in the microscopic structure of tenocytes between the control group and the groups treated with fluoroquinolones including dilatations, vesicles and vacuoles in the cytoplasm that had developed due to swellings of the rough endoplasmic reticulum. As an individual, the mitochondria have heavily damaged tenocytes that detached from the surrounding and extracellular matrix was detected in specimens which are treated with floroquinolones [36].

\section{Comparison with other fluoroquinolones}

An in-vitro survey has compared levofloxacin and ciprofloxacin activity and toxicity. In which, ciprofloxacin represents a higher intrinsic activity than levofloxacin with respect to the tendotoxic action [26]. While in other case study, 2539 tendon rupture were related to levofloxacin (61\%), before ciprofloxacin (24\%) and moxifloxacin (9\%) where gemifloxacin, lomefloxacin and trovafloxan had the lowest risk of tendon rupture [37]. Besides, the possibility of tendon rupture for ofloxacin and ciprofloxacin are estimated as $2.7 / 1000$ patients and $0.9 / 1000$ patients respectively [38]. The number of reports for tendinitis and tendon rupture within two months of onset of therapy with norfloxacin was 3 per 1000 patients [39]. Among 421 cases from databases, 68\% were attributed to pefloxacin, 18\% were attributed to ofloxacin and 5\% of them were for ciprofloxacin [40].

A study has analysed the 2235000 patients treated by mixofloxacin, among which there were no tendonitis [41]. Although ultrastructural changes have been shown in the Achilles tendons from immature rats treating with gemifloxacin, there are still no case reports available in human patients [42]. An in-vivo study was made on group of rats, among which ten are tested with fluoroquinolones, fleroxacin and pefloxacin caused lesions at a dose of $100 \mathrm{mg} / \mathrm{kg}$ of or more and lomefloxacin, levofloxacin and ofloxacin induced tendon lesion at the dose of $300 \mathrm{mg} / \mathrm{kg}$ while sparfloxacin and enoxacin has the same effect at the dose of 900 $\mathrm{mg} / \mathrm{kg}$ or more. It is interesting to note that in this experiment three of those fluoroquinolones (norfloxacin, ciprofloxacin, and tosufloxacin) had no effects on Achilles tendon even at the high dose of $900 \mathrm{mg} / \mathrm{kg}$ [43].

In conclusion, in-vivo, in-vitro and structural surveys have shown that florouquinolones especially Ciprofloxacin can cause tendon rupture and tendinitis. Although it is not still clear which floroquinolones is the most riskful one in tendon disorders, it has been indicated that the risk of tendon disorders by ciprofloxacin treatment is not deniable.

\section{CONCLUSION}

After all, this review illustrates that ciprofloxacin has some negative effect upon tendon structure. In all presented cases several days or weeks after ciprofloxacin treatment cessation, improvement has appeared.

Besides, Ciprofloxacin has shown apoptotic impression on tendon cells in in-vitro experiments. Alteration in tendon structure ranging from development of swollen cell organelles and apoptotic bodies to degradation in interleukin-1 $\beta$ after ciprofloxacin consumption is evident.

Tendinopathy is not entered to the text books as ciprofloxacins' side effect possibility is around $3.5 \%$. So, it is important to have more studies in this field and aware doctors and specialist to prescribe ciprofloxacin with caution especially in risky cases since drug safety is one the most important debates nowadays; drugs with health threating effects on patients should be substituted by more safe drugs. Studies have shown that with new floroquinolones, no case report of tendon disorders has been presented and more data about this subject needs more precise study [37].

\section{REFERENCES}

1. Van Der Linden PD, Van Puijenbroek EP, Feenstra J, Veld BA, Sturkenboom MC, Herings RM, et al. Tendon disorders attributed to fluoroquinolones: A study on 42 spontaneous reports in the period 1988 to 1998. Arthritis Care Res. 2001;45(3):235-239.

2. Pantalone A, Abate M, D'Ovidio C, Carnevale A, Salini V. Diagnostic failure of ciprofloxacin-induced spontaneous bilateral achilles tendon rupture: Case-report and medical-legal considerations. Int J Immunopathol Pharmacol. 2011;24(2):519-522.

3. McGarvey WC, Singh D, Trevino SG. Partial achilles tendon ruptures associated with fluoroquinolone antibiotics: A case report and literature review. Foot Ankle Int. 1996;17(8):496-498.

4. Katzung BG, Masters SB, Trevor AJ. Basic \& Clinical Pharmacology. 2004.

5. Kaminski MM, Sauer SW, Klemke CD, Süss D, Okun JG, Krammer $\mathrm{PH}$, et al. Mitochondrial reactive oxygen species control T cell activation by regulating IL-2 and IL-4 expression: mechanism of ciprofloxacinmediated immunosuppression. J Immunol. 2010;184(9):4827-4841.

6. Kaatz GW, Seo SM. Mechanism of ciprofloxacin resistance in Pseudomonas aeruginosa. J Infect Dis. 1988;158(3):537-541.

7. Leone R, Venegoni M, Motola D, Moretti U, Piazzetta V, Cocci A, et al. Adverse drug reactions related to the use of fluoroquinolone antimicrobials. Drug saf. 2003;26(2):109-120.

8. Fish DN. Fluoroquinolone adverse effects and drug interactions. 
Pharmacotherapy. 2001;21(10 Pt 2):253S-272S.

9. Domagala JM. Structure-activity and structure-side-effect relationships for the quinolone antibacterials. J Antimicrob Chemother. 1994;33(4):685-706

10. Moretti MV, Pauluzzi S, Cesana M. Penetration of rufloxacin into the cerebrospinal fluid in patients with inflamed and uninflamed meninges. Antimicrob Agents Chemother. 2000;44(1):73-77.

11. De Sarro A, Cecchetti V, Fravolini V, Naccari F, Tabarrini O, De Sarro G. Effects of novel 6-desfluoroquinolones and classic quinolones on pentylenetetrazole-induced seizures in mice. Antimicrob Agents Chemother. 1999;43(7):1729-1736.

12. Ball P. Ciprofloxacin: An overview of adverse experiences. J Antimicrob Chemother. 1986;18(Suppl D):187-193.

13.Stahlmann R. Clinical toxicological aspects of fluoroquinolones. Toxicol Lett. 2002;127(1):269-277.

14. Stahlmann R, Lode H. Toxicity of quinolones. Drugs. 1999;58(2):3742.

15.Tsai WC, Hsu CC, Chen CP, Chang HN, Wong AM, Lin MS, et al. Ciprofloxacin up-regulates tendon cells to express matrix metalloproteinase-2 with degradation of type I collagen. J Orthop Res. 2011;29(1):67-73

16. Corps AN, Curry VA, Harrall RL, Dutt D, Hazleman BL, Riley GP. Ciprofloxacin reduces the stimulation of prostaglandin E2 output by interleukin-1 $\beta$ in human tendon-derived cells. Rheumatology (Oxford). 2003;42(11):1306-1310.

17. Damuth E, Heidelbaugh J, Malani PN, Cinti SK. An elderly patient with fluoroquinolone-associated Achilles tendinitis. Am J Geriatr Pharmacother. 2008;6(5):264-268.

18. Akali AU, Niranjan NS. Management of bilateral Achilles tendon rupture associated with ciprofloxacin: a review and case presentation. J Plast Reconstr Aesthet Surg. 2008;61(7):830-834.

19. Karistinos A, Paulos LE. "Ciprofloxacin-induced" bilateral rectus femoris tendon rupture. Clin J Sport Med. 2007;17(5): p. 406-407.

20.Mouzopoulos G, Stamatakos M, Vasiliadis G, Skandalakis P. Rupture of adductor longus tendon due to ciprofloxacin. Acta Orthopaedica Belgica. 2005;71(6): 743 .

21. Ozaras R, Mert A, Tahan V, Uraz S, Ozaydin I, Yilmaz MH, et al. Ciprofloxacin and achilles' tendon rupture: A causal relationship. Clin Rheumatol. 2003;22(6):500-501.

22.Movin T, Gad A, Güntner P, Földhazy Z, Rolf C. Pathology of the achilles tendon in association with ciprofloxacin treatment. Foot Ankle Int. 1997;18(5):297-299.

23.Muzi F, Gravante G, Tati E, Tati G. Fluoroquinolones-induced tendinitis and tendon rupture in kidney transplant recipients: 2 cases and a review of the literature. Transplant Proc. Elsevier. 2007.

24.Casparian JM, Luchi M, Moffat RE, Hinthorn D. Quinolones and tendon ruptures. South Med J. 2000;93(5): 488-491.

25.uston KA. Achilles tendinitis and tendon rupture due to fluoroquinolone antibiotics. N Engl J Med. 1994;331(11):748.

26.Sendzik J, Shakibaei M, Schäfer-Korting M, Stahlmann R. Fluoroquinolones cause changes in extracellular matrix, signalling proteins, metalloproteinases and caspase-3 in cultured human tendon cells. Toxicology. 2005:212(1):24-36

27. Corps AN, Harrall RL, Curry VA, Fenwick SA, Hazleman BL, Riley GP. Ciprofloxacin enhances the stimulation of matrix metalloproteinase 3 expression by interleukin- $1 \beta$ in human tendon-derived cells. Arthritis Rheum. 2002;46(11):3034-3040.
28. Williams RJ, Attia E, Wickiewicz TL, Hannafin JA. The effect of ciprofloxacin on tendon, paratenon, and capsular fibroblast metabolism. Am J Sports Med. 2000;28(3):364-369.

29.Pouzaud F, Bernard-Beaubois K, Thevenin M, Warnet JM, Hayem G, Rat P. In vitro discrimination of fluoroquinolones toxicity on tendon cells: involvement of oxidative stress. J Pharmacol Exp Ther. 2004;308(1):394-402.

30.Chalumeau M, Tonnelier S, D'Athis P, Tréluyer JM, Gendrel D, Bréart $\mathrm{G}$, et al. Fluoroquinolone safety in pediatric patients: A prospective, multicenter, comparative cohort study in France. Pediatrics. 2003;11(6):e714-e719.

31.van der Linden PD, Sturkenboom MC, Herings RM, Leufkens HM, Rowlands S, Stricker BH. Increased risk of achilles tendon rupture with quinolone antibacterial use, especially in elderly patients taking oral corticosteroids. Arch Intern Med. 2003;163(15):1801-1807.

32. Corrao G, Zambon A, Bertù L, Mauri A, Paleari V, Rossi C, et al. Evidence of tendinitis provoked by fluoroquinolone treatment. Drug saf. 2006;29(10):889-896.

33.Chhajed PN, Plit ML, Hopkins PM, Malouf MA, Glanville AR. Achilles tendon disease in lung transplant recipients: association with ciprofloxacin. Eur Respir J. 2002;19(3):469-471.

34.Kim GK. The risk of fluoroquinolone-induced tendinopathy and tendon rupture: what does the clinician need to know? J Clin Aesthet Dermatol. 2010;3(4):49-54.

35.Zargar BN, Poulsen RC, Franklin SL, Thompson MS, Hulley PA. Platelet-rich plasma protects tenocytes from adverse side effects of dexamethasone and ciprofloxacin. Am J Sports Med. 2011;39(9):1929. 1935.

36.Shakibaei M, Pfister K, Schwabe R, Vormann J, Stahlmann R. Ultrastructure of achilles tendons of rats treated with ofloxacin and fed a normal or magnesium-deficient diet. Antimicrob Agents Chemother. 2000;44(2):261-266.

37. Arabyat RM, Garg V, Raisch DW, Bennett C. Fluoroquinoloneassociated tendon-rupture: a summary of reports in the food and drug administration's (Fda's) adverse event reporting system. Value Health. 2013;16(3):A217

38.Tsai WC, Yang YM. Fluoroquinolone-associated tendinopathy. Chang Gung Med J. 2011;34(5):461-467.

39. Wilton LV, Pearce GL, Mann RD. A comparison of ciprofloxacin, norfloxacin, ofloxacin, azithromycin and cefixime examined by observational cohort studies. Br J Clin Pharmacol. 1996;41(4):277-284.

40.Khaliq Y, Zhanel GG. Fluoroquinolone-associated tendinopathy: A critical review of the literature. Clin Infect Dis. 2003;36(11):1404-1410.

41. Saravolatz LD, Leggett J. Gatifloxacin, gemifloxacin, and moxifloxacin: The role of 3 newer fluoroquinolones. Clin Infect Dis. 200;37(9):12101215 .

42.Bae CS, Oh DM, Bae JG, Kim JC, Kim SH, Kim SG, et al. Ultrastructural changes of the gemifloxacin on Achilles tendon in immature rats: comparison with those of ciproxacin and ofloxacin. Basic Clin Pharmacol Toxicol. 2006;98(4):406-410.

43.Kashida Y, Kato M. Characterization of fluoroquinolone-induced achilles tendon toxicity in rats: comparison of toxicities of 10 fluoroquinolones and effects of anti-inflammatory compounds. Antimicrob Agents Chemother. 1997;41(11):2389-2393. 